Article

\title{
Impact of Perceived Organizational Support on Work Engagement: Mediating Mechanism of Thriving and Flourishing
}

\author{
Muhammad Yasir Imran ${ }^{1}$, Natasha Saman Elahi ${ }^{1, *(D)}$, Ghulam Abid ${ }^{1,2} \mathbb{D}$, Fouzia Ashfaq ${ }^{3}$ \\ and Sehrish Ilyas ${ }^{3}$ \\ 1 School of Business Administration, National College of Business Administration and Economics, \\ Lahore 54000, Pakistan; yasir.imran1991@gmail.com (M.Y.I.); ghulam.abid@kinnaird.edu.pk or \\ dr.ghulamabid@gmail.com (G.A.) \\ 2 Department of Business Studies, Kinnaird College for Women Lahore, Lahore 54000, Pakistan \\ 3 Department of Management Sciences, Lahore College for Women Lahore, Lahore 54000, Pakistan; \\ Fouzia.Ashfaq@lcwu.edu.pk (F.A.); Sehrish.Ilyas@lcwu.edu.pk (S.I.) \\ * Correspondence: natashasaman20@gmail.com
}

Received: 17 August 2020; Accepted: 3 September 2020; Published: 14 September 2020

\begin{abstract}
Based on organizational support theory, this study examined the indirect influence of perception of organizational support on employee work engagement with the mediating influence of flourishing and thriving at work. Data were collected by utilizing the self-administered questionnaires related to study variables in two different time periods. Using PROCESS Macros on an actual sample of 638 employees, the study found that perceived organizational support was positively associated with employee flourishing, thriving, and work engagement. Moreover, perceived organizational support indirectly influences work engagement via thriving and flourishing. The study provides many insights into evolving constructs (i.e., thriving and flourishing) and examines how organizations can create the psychological state and well-being (hedonic and eudemonic) of employees through the perception of organizational support.
\end{abstract}

Keywords: perceived organizational support; thriving at work; flourishing; work engagement

\section{Introduction}

To remain competitive and successful, organizations have to adjust themselves swiftly to a dynamic environment [1] and also permit their employees to thrive in the workplace [2-4]. Thriving personnel are considered as a source of competitive advantage $[5,6]$ and contribute a very important role in organizational success because thriving employees perform better [7], stay healthier, are proactive, self-learners, career-oriented, and disburse higher attention toward organizational goals [8-10]. Empirical studies have also shown that thriving is a predictor of organizational support for innovation [11], happiness [12], life satisfaction, [13], and job satisfaction [14]. Likewise, thriving has a positive association with health, job satisfaction, self-development, citizenship behavior; commitment toward organizations, task and creative performance, and organizational citizenship behavior also has a negative association with burnout and turnover intention [6].

Many studies have underlined the significance of thriving in the setting of an organization [15]. Based on the socially embedded model, many relational characteristics (e.g., supervisor workplace support, co-worker workplace support, and workplace civility) have been identified that have prompted employees to thrive at work, which in turn creates positive outcomes $[5,6,12,13,15,16]$. In spite of the effect of these relational factors on thriving, limited studies have observed the perception of the organization (relational factor) effect on thriving in the work setting of a South Asian context. 
For this reason, we proposed that perceived organizational support (POS) is positively influenced thriving, which leads to positive outcomes (i.e., work engagement). POS is described by Eisenberger et al. [17] as to what degree employees perceived that their organizations valued their contributions, cared about their well-being, and also fulfilled their socio-emotional needs (i.e., esteem, approval, and affiliation). Researchers $[4,18]$ characterized thriving as a mutual connection of learning and vitality in the workplace. Vitality is described as a sense of aliveness and positive energy, while acquisition and utilization of skills and knowledge to build capability and confidence is known as learning.

The notion of flourishing has become more and more interesting to scholars $[19,20]$. Thus far, there are limited studies that have investigated the predictors of flourishing [21]. For instance, Janse van Rensburg et al. [22] explained that supportive supervision is a contributor to flourishing. Demerouti et al. [23] empirically affirmed that job crafting prompts the employees to flourish at work; however, the influence of perceived organizational support on flourishing at work has not been examined by earlier studies to the best of our knowledge. Therefore, in this study, we examined the predictors of flourishing, and proposed that POS enhanced flourishing at work to fill this void. Keyes [24] characterized flourishing as the intersection of eudemonic and hedonic well-being. Furthermore, in the working context, the positive outcomes of flourishing are under research [25] and few studies have identified the beneficial outcomes of flourishing at work such as creativity, subjective well-being, and lower turnover intention [26,27]. Researchers have not empirically tested whether flourishing employees exhibited excellent engagement with their work. Hence, we have been more persuaded to examine the flourishing and work engagement association for contemplate this gap. Furthermore, we anticipate that POS indirectly impacts work engagement with the mediating effect of flourishing as well as thriving at work.

Hence, this study aimed to answer the following research questions in the services sector of Pakistan: Does POS positively influence thriving and flourishing and work engagement? Does POS indirectly influence employee engagement via mediators of thriving and flourishing? The core goals of this study were (1) to inspect the association among POS, flourishing, work engagement, and thriving at work; and (2) to examine the indirect impact of POS on work engagement through thriving and flourishing at work. The rest of this paper is structured as follows. Section 2 presents detailed information about the variables [i.e., POS (perceived organizational support), thriving, flourishing, and work engagement] as well as hypotheses formulation. Section 3 describes the method of the study, which incorporates population, sampling, and the data collection procedure. Section 4 presents the data analysis technique and interpretation of the study results. In Section 5, the relationship between thriving, flourishing, and open innovation is discussed. Section 6 presents the theoretical and practical implication with certain study limitations and the conclusions of our study.

\section{Literature Review and Hypotheses Development}

In this study, we drew on organizational support theory and conservation of resource theory as the overarching framework to examine the indirect influence of perception of organizational support on work engagement with the mediators of flourishing and thriving. Organizational support theory (OST) is considered as an important theoretical foundation of perception of organizational support entrenched with social exchange theory [28]. For this reason, in the study, we used organizational support theory to examine the effect of POS on employee work engagement by flourishing and thriving. We suggest that when employees assume that their organizations provide them with intangible and tangible support, a norm of reciprocity creates a feeling of obligation among employees [29] that drives them to help their organizations to achieve their goals [17]. A reciprocity norm recommends that employees with high POS pay off their organizations in the form of flourishing, thriving, and by engaging in their work. Likewise, we advocated that employees would show more engagement toward their works, will flourish more, be energetic, and also more inclined to learning new knowledge and skills when they perceive their organization as being more supportive, and fulfilling their socio-emotional needs, for example, affiliation, self-esteem, appreciation, and approval [30]. Therefore, employees who 
perceived that their organizations reward their contributions as a result of its employees flourishing, work engagement, and thriving will be elevated.

Management scholars have presented COR theory to explain the associations between workplace support and its beneficial outcomes in the working context [13]. Therefore, in this study, we drew on COR theory to support our hypothetical model. The fundamental precept of COR is that people make an effort to obtain, retain, protect, and foster the resources that they value [31]. These resources are precious to personnel because they encourage them to show positive behaviors. In the present research, we anticipate that perception of organizational support facilitates the resource caravans, and the creation of resources persuades employees to thrive in the work context, which will enhance employee engagement toward their work. Organizational context either encourages or deprives the individual's resources [32]. Thriving at work is a personal resource that takes place through the combination of feeling energetic and learned, and POS encourages employees to generate cognitive (learning) and affective (vitality) resources [13]. It also protects their resources and consents them to develop new resources such as affective and cognitive resources [32], which prompts work engagement. We also suggested that employees create and invest their finite amount of sources (personal and social resources) in the presence of POS, where as a result they will flourish. Flourishing employees have plenty of sources that encourage work engagement.

\subsection{Linking Perceived Organizational Support and Work Engagement}

Hakkak and Ghodsi [33] described POS as a kind of cooperation or support that is necessary to carry out a job effectively. In contrast, work engagement is a multidimensional concept and is described as a positive, fulfilling, and work-related state of mind that consists of three elements: vigor (physical element), dedication (emotional element), and absorption (cognitive element). Vigor is illustrated when employees feel mental resilience and energy at a greater extent when they work. Dedication is comprised of significance, inspiration, pride, challenge, enthusiasm, and involvement in the work. Absorption occurs when employees have a high concentration level and are immensely engrossed in their work, wherein time moves rapidly and they feel obscurity to disengage themselves from work [34]. We proposed that job resource is the POS effect engagement of employees at work in a positive manner in this study. The previous study stated that when employees have POS, it reinforces their emotional and cognitive assessment of their organization and work [35]. Employees with greater POS may become more engaged in their work and organizations as part of social exchange theory's reciprocity norm to help out the organization in the achievement of its goals.

This indicates that employees, when thinking that their organization valued their contributions, and perceive that their well-being was more of concern about them as a result of it, are probably likely to repay their organization by trying to meet their organizational related obligations by becoming more engaged. POS positively impacts employee work engagement as it reinforces the intrinsic interest among them for their duties and tasks. For four primary reasons, the perception of the organization will encourage the intrinsic interest of employees in their duties. For example, first, POS encourages the belief of their employees that when they need it, their organization will provide emotional or material support. Second, POS meets the socio-emotional needs of employees such as affiliation and esteem needs. Third, POS may convey high rewards for good performance to employees. Fourth, it could boost the intrinsic interest of employees for their tasks by enhancing their self-efficacy [36]. POS is an important driver of work engagement [37]. Another study of Ali et al. [38] explained that employees were highly engaged in their work when they perceived their organization provided support to them. Researcher [39] found that work engagement was endorsed by POS. Employees were seen to be more engaged with their work in highly supportive organizations. So, we posit:

Hypothesis 1 (H1). Perceived organizational support is positively related to work engagement. 


\subsection{Linking Perceived Organizational Support and Thriving}

In an existing study, we supposed that POS was positively related to thriving at work, as aligned with OST and COR theory. This support was received from studies such as by Abid et al. [40] and Kleine et al. [6] where they found that POS enabled employees to thrive in the workplace. Employees felt full of vitality when they perceived that the organization regarded their contributions, cared for their wellbeing, and also fulfilled their socio-emotional needs. In a supportive work environment, employees can acquire new knowledge, information, refine their skills and also investigate problems and find new solutions through interaction [16]. Employees were energetic in gaining knowledge of new things and applying these skills and information to carry out their tasks at work when they received support from their supervisor and organization. Rhoades and Eisenberger [41] indicated that employees with a higher perception of organizational support felt better at work, found their jobs more pleasant, and also endured fewer strain signs, for example, burnout or fatigue. This specified that POS encourages the experience of vitality. Eisenberger et al. [30] stated that higher verifiable support generates the obligations within people to pay back their organizations by contributing to its success that is far beyond their official requirements. Therefore, employees who believed that their organization gave more support to them ought to be further encouraged to procure the skills and knowledge to assist their organization in the accomplishment of its goals, thus promoting learning in the workplace. We posit that employees will thrive in a working environment if they perceived that their organization is more supportive to them [30].

Hypothesis 2 (H2). Perceived organizational support is positively related to thriving at work.

\subsection{Linking Thriving and Work Engagement}

Bakker et al. [42] signified that to some extent, work engagement and thriving theoretically overlap each other, but can be viewed as two distinct constructs. Thriving as well as work engagement incorporate an energy element such as vigor and vitality, however, work engagement involves more elements such as dedication and absorption, whereas thriving involves another element (i.e., learning). On the other hand, the distinction between work engagement and thriving could be based on resource allocation and development. Work engagement describes the degree to which employees eagerly utilized their resources at the workplace, recognizing how much individuals felt that their job provided them with self-improvement, which is dependent on resource construction [4]. Favoring the hypothetical statements of Abid et al. [5] and van der Walt [43] who found that thriving employees were highly engaged in their work, we proposed that thriving employees show more engagement toward their work. While taking on difficult duties and tasks, thriving employees feel energized.

Energetic individuals show persistence and higher energy to perform all tasks and duties for the achievement of their own goals [44]. Learning employees gain expertise and skills and apply them confidently to situations, in this way, becoming more capable of performing tasks. Demerouti et al. [45] stated that employees could be kept engaged by offering an atmosphere of learning. Given that these personnel use their big pool of long-term resources to care about the forecasting of outcomes [46] and to shun anxiety, stress, and pressure due to difficult circumstances [47]. Thriving people apply higher energy to their jobs and are energetically engaged in their work [48]. Employees' personal development and their readiness to give their full effort toward obligations that are associated with work are enhanced by these resources, which ultimately affect their job as well as personal outcomes in a positive manner [37].Therefore, we propose:

Hypothesis 3 (H3). Thriving is positively related to work engagement.

We also presumed that POS indirectly influences work engagement via thriving. POS protects their resources and allows them to develop new cognitive and affective resources when employees are highly energetic and more inclined for the acquisition of knowledge and skilled work as a result of it 
so are exceedingly engaged in their work. In line with OST, thriving employees are very engaged in their work when they perceive that their organization is more supportive of them. Hence, we posit:

Hypothesis 4 (H4). Perceived organizational support indirectly influences work engagement through thriving.

\subsection{Linking Perceived Organizational Support and Flourishing}

Flourishing depicts an individual's life at the optimum level of human functioning and can be typified as growth, resilience, goodness, and generativity [49]. Keyes [24] introduced the idea of flourishing; it relates to the pattern of positive functioning and emotions in life that includes the three facets of well-being such as emotional, psychological, and social. Scholars have identified the factor that can enable employees to flourish in the workplace. For instance, Rautenbach and Rothmann [27] found in their study that advancement and authentic leadership were predictors of flourishing. Butt et al. [26] showed that energy and flourishing were positively related to each other. In this study, we anticipated that POS enhanced flourishing at work. Thus, we suggest that employees would flourish when they perceived that their organization was more supportive and fulfilled their socio-emotional needs, so flourishing will be enhanced when significant resources that are related to job (i.e., POS) are presented. Thus, we anticipate:

Hypothesis 5 (H5). Perceived organizational support is positively related to flourishing.

\subsection{Linking Flourishing and Work Engagement}

Flourishing is usually used to define the high level of well-being. Flourishing employees perform and feel better in the workplace in comparison to languishing people [19].Employees who flourish at work have a higher resilience toward life challenges and vulnerabilities; they are also more mentally and physically fit than languishing employees. Flourishing people experience less helplessness; they achieve higher positions in the working context. They are more creative [23] and experience more favorable emotions when compared to adverse emotions [27]. They widen their expertise in the job, engender a sense of meaningful life and competency among themselves and nurture as a human being. Employees' experience of positive sentiments enables them to feel good and perform all duties in an effective way [50]. Employees who flourish at work create personal and social resources over time that subsequently encourages their engagement at work. Flourishing employees have plenty of resources, which is why they are more willing to utilize it in their work and also show positive behavior such as work engagement. Thus, in line with the above discussion, we posit that:

Hypothesis 6 (H6). Perceived organizational support is positively related to flourishing.

We also supposed that POS indirectly influences work engagement via flourishing. Employees create and invest a finite amount of personal and social resources in the presence of organizational support, which as a result, they flourish. Flourishing employees have plenty of resources that encourage work engagement as explained by resource conservation theory [51]. Thus, we postulate that:

Hypothesis 7 (H7). Perceived organizational support indirectly influences the work engagement relationship by flourishing.

All study relationships are summarized in Figure 1. 


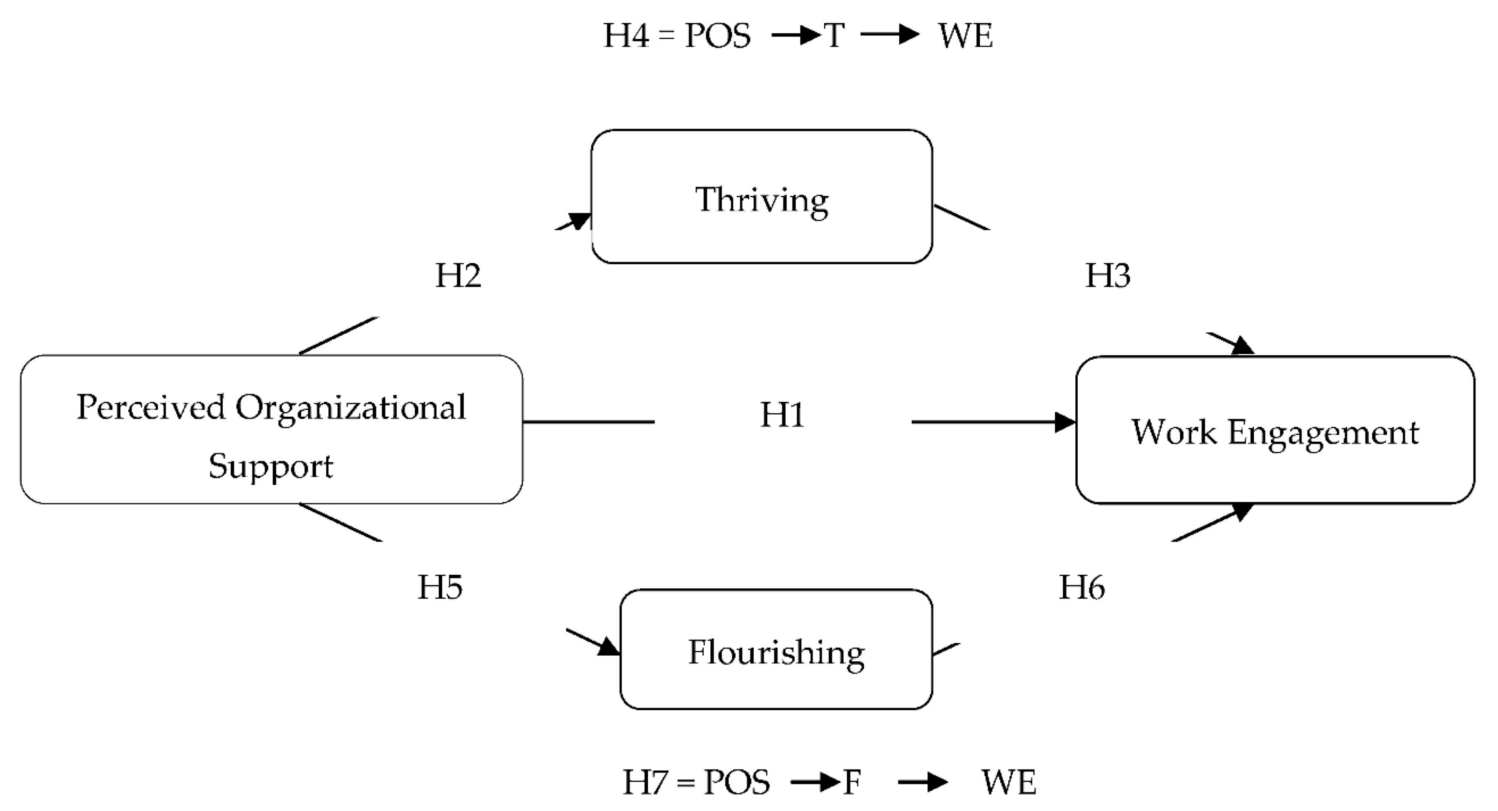

Figure 1. Theoretical framework.

\section{Methods}

\subsection{Sample and Procedure}

The targeted population was working employees of the service sector, particularly the banking sector of Lahore (Punjab), Pakistan. The data were collected from employees in a non-contrived setting with minimal interference by researchers by confirming with the respondents that their information would be kept confidential if they felt hesitant in giving their information to the study. Data were collected over two different periods of time through self-administered questionnaires in cross-sectional time horizon to minimize the common method biases [52] (See Figure 2). A total of 900 questionnaires were distributed to the sampled employees. Upon deleting incomplete responses and matching employee responses at two different times T1 and T2, a total 638 questionnaires was established. Therefore, the actual sample size was 638 with a $70 \%$ response rate. The majority of respondents were male 431 (67.6\%) while 207 (32.4\%) were female. A total of 344 (53.9\%) respondents were single, while 290 (45.5\%) respondents were married. Most employees belonged to the 20-29 year old age group $(56.1 \%), 446$ (69.9\%) respondents had 0-5 years of work experience with their current organization, and out of 638 , the majority of employees had graduated $(524,82.2 \%)$.

\subsection{Measures}

For the measuring variables, a well-established measure was used (see Appendix A). POS and thriving were calculated with a Likert scale of five points ranging from 1 (strongly disagree) to 5 (strongly agree). The 8-item scale of Eisenberger et al. [53] was used for estimation of POS. An example includes "My organization strongly considers my goals and values". The 10-item scale of Porath et al. [18] was used to assess thriving at work. A sample item from the vitality dimension is "I feel alive and vitality". Flourishing was measured using the 8-item scale of Diener et al. [19] where an example includes "I lead a purposeful and meaningful life". Items were assessed on a six-point Likert scale ranging from 1 (very strongly disagree) to 6 (very strongly agree). The 9-item scale of Schaufeli et al. [34] was used for the estimation of work engagement. Scores were anchored on a seven-point Likert scale (1) never to 7 (always). A sample item includes "At my work, I feel bursting with energy". 


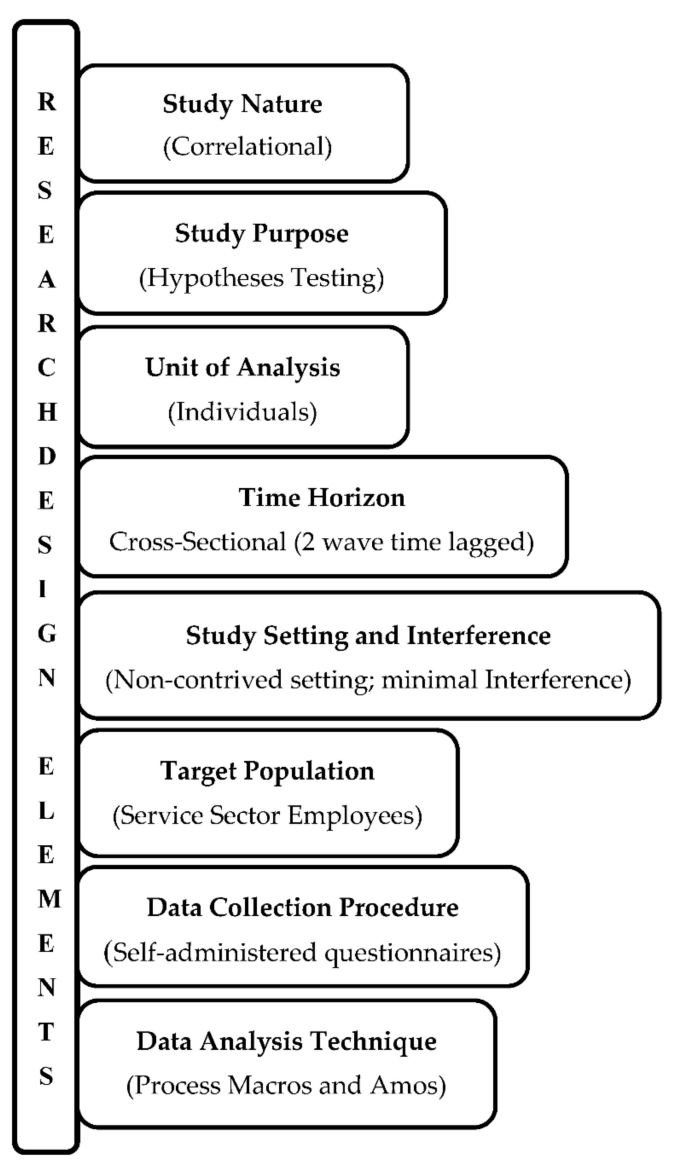

Figure 2. Research design elements.

\section{Results}

\subsection{Correlation Matrix}

In line with our proposed hypothetical statements, the correlation analysis showed that POS has a positive and significant relation with work engagement $(r=0.38, p<0.01)$ and thriving $(r=0.39$, $p<0.01)$. Results showed that the significant effect of thriving with work engagement was positive $(r=0.55, p<0.01)$. Results showed that POS positively impacted flourishing $(r=0.13, p<0.01)$ and that flourishing at work and work engagement were positively associated with each other $(r=0.27$, $p<0.01$ ). Furthermore, correlation analysis did not find any association among the study variables and demographics (See Table 1).

Table 1. Means, standard deviations, and Intercorrelations.

\begin{tabular}{lccccccccccc}
\hline \multicolumn{1}{c}{ Variables } & Mean & S.D & $\mathbf{1}$ & $\mathbf{2}$ & $\mathbf{3}$ & $\mathbf{4}$ & $\mathbf{5}$ & $\mathbf{6}$ & $\mathbf{7}$ & $\mathbf{8}$ \\
\hline 1. Marital Status & 1.47 & 0.52 & - & & & & & & & \\
2. Age & 2.50 & 0.73 & $0.62 * *$ & - & & & & & & \\
3. Education & 15.74 & 1.43 & $0.10^{* *}$ & $0.12^{* *}$ & - & & & & & \\
4. Tenure & 1.44 & 0.84 & $0.45^{* *}$ & $0.71^{* *}$ & -0.02 & - & & & \\
5. Perceived Organizational Support & 3.78 & 0.69 & -0.03 & 0.02 & -0.07 & -0.03 & $(0.90)$ & & \\
6. Thriving at Work & 4.16 & 0.53 & -0.01 & -0.02 & -0.04 & -0.04 & $0.39^{* *}$ & $(0.89)$ & \\
7. Flourishing & 4.61 & 0.79 & -0.03 & 0.00 & -0.02 & 0.01 & $0.13^{* *}$ & $0.29^{* *}$ & $(0.91)$ \\
8. Work Engagement & 4.57 & 0.96 & 0.02 & 0.04 & -0.07 & 0.03 & $0.38^{* *}$ & $0.55^{* *}$ & $0.27^{* *}$ & $(0.89)$ \\
\hline
\end{tabular}

$\mathrm{N}=638$, Alphas values are on the diagonal in parenthesis. ${ }^{* *} p<0.01$.

\subsection{Measurement Validation}

By utilizing the principal component analysis with Varimax, factor analysis was carried out on data obtained from 638 respondents. Bartlett's test (sphericity measure) and the KMO (Kaiser Myer 
Olkin) test for sample adequacy were conducted to recognize the factor analysis appropriateness. The KMO (measure of sampling adequacy) value was 0.92 , which surpassed the threshold value of 0.60 suggested by Kaiser [54]. This test confirmed that data was appropriate for factor analysis. Bartlett's test of all factors reached statistical significance with $p<0.001$, which indicated that Bartlett's test for all factors was significant. The four factors explained the total variance of $59.55 \%$, which was greater than $50 \%$. In this analysis, all factor loading of items were above the absolute value of 0.60 , which was in accordance with the general rule of thumb that the loading of an item is considered higher when it is greater than 0.60 [55].

In the factor analysis, first, eight items were loaded on the first factor that belonged to perceived organizational support. The next 10 items that belonged to thriving were loaded on the second factor, where two items (i.e., T4) were eliminated because the loading was 0.4. According to [56], items with 0.4 or less than 0.4 would be eliminated from factor analysis. In addition, one item of thriving at work (i.e., T8) was unable to be loaded on the main factor and made another factor, therefore, this item were eliminated during factor analysis. The next eight items that belonged to flourishing were loaded on the third factor, and finally, nine items that belonged to work engagement were loaded on the fourth factor. The factor loading of perceived organizational support ranged from 0.690 to 0.798 , factor loading of thriving ranged from the 0.677 to 0.741 , factor loading of flourishing ranged from 0.742 to 0.801 , and the factor loading of work engagement ranged from 0.513 to 0.789 . The results indicate that in the study, each variable was independent of other variables and each item was related to the expected factor structure. Table 2 shows the matrix of the final factor loading.

Table 2. Exploratory factor analysis.

\begin{tabular}{|c|c|c|c|}
\hline $\begin{array}{c}\text { Factor 1-Perceived } \\
\text { Organizational Support }\end{array}$ & Factor Loading & Factor 3-Flourishing & Factor Loading \\
\hline POS1 & 0.768 & FLO1 & 0.753 \\
\hline POS2 & 0.791 & FLO2 & 0.764 \\
\hline POS3 & 0.798 & FLO3 & 0.742 \\
\hline POS4 & 0.706 & FLO4 & 0.801 \\
\hline POS5 & 0.755 & FLO5 & 0.786 \\
\hline POS6 & 0.690 & FLO6 & 0.798 \\
\hline POS7 & 0.760 & FLO7 & 0.779 \\
\hline POS8 & 0.763 & FLO8 & 0.755 \\
\hline Eigenvalue & 3.15 & Eigenvalue & 4.35 \\
\hline$\%$ of Total Variance Explained & 9.56 & $\%$ of Total Variance Explained & 13.20 \\
\hline Factor 2-Thriving at Wok & Factor Loading & Factor 4-Work Engagement & Factor Loading \\
\hline $\mathrm{T} 1$ & 0.741 & WE1 & 0.563 \\
\hline T2 & 0.717 & WE2 & 0.727 \\
\hline $\mathrm{T} 3$ & 0.731 & WE3 & 0.696 \\
\hline $\mathrm{T} 5$ & 0.677 & WE4 & 0.789 \\
\hline T6 & 0.682 & WE5 & 0.749 \\
\hline T7 & 0.693 & WE6 & 0.761 \\
\hline T9 & 0.678 & WE7 & 0.770 \\
\hline T10 & 0.680 & WE8 & 0.787 \\
\hline Eigenvalue & 2.16 & WE9 & 0.513 \\
\hline$\%$ of Total Variance Explained & 6.54 & Eigenvalue & 9.98 \\
\hline \multicolumn{4}{|c|}{ Total Variance (\%) 59.55} \\
\hline
\end{tabular}

In addition, the results of the confirmatory factor analysis (CFA) outcomes demonstrated that the fit indices value of four-factor model, in other words, POS, thriving, flourishing, and work engagement fit best with our dataset because all values of fit indices exceeded the acceptable values of Adjusted Goodness Fit Index (AGFI) $>0.86$, chi-square/degrees of freedom $\left(\chi^{2} /(\mathrm{df})<3\right.$, Root Mean Square Error of Approximation (RMSEA) $<0.08$, Comparative Fit Index (CFI) > 0.90, Root Mean Square Residual $($ SRMR) $<0.05$, Turkish Lower Index (TLI) $>0.90$, and Incremental Fit Index (IFI) $>0.90$ [57] in comparison to all alternative models (See Table 3; Figure 3). 
Table 3. Fit indices of factor models.

\begin{tabular}{cccccccccc}
\hline Models & $\chi^{\mathbf{2}}$ & $\mathbf{d f}$ & $\chi^{\mathbf{2}} / \mathbf{d f}$ & TLI & IFI & CFI & AGFI & SRMR & RMSEA \\
\hline Hypothetical Model $^{1441.06}$ & 487 & 2.95 & 0.91 & 0.92 & 0.95 & 0.86 & 0.04 & 0.05 \\
Model 1 $^{\mathrm{a}}$ & 4268.57 & 492 & 8.67 & 0.65 & 0.68 & 0.88 & 0.52 & 0.13 & 0.11 \\
Model 2 $^{\mathrm{b}}$ & 5648.11 & 494 & 11.43 & 0.53 & 0.89 & 0.56 & 0.41 & 0.13 & 0.12 \\
Model 3 $^{\mathrm{c}}$ & 6919.97 & 496 & 13.98 & 0.42 & 0.85 & 0.46 & 0.37 & 0.14 & 0.14 \\
\hline
\end{tabular}

${ }^{a}$ Three-factor: POS and flourishing merged into one factor; ${ }^{\mathrm{b}}$ Two-factor: POS and thriving merged into one factor; flourishing and work engagement merged into one factor; ${ }^{c}$ Single-factor: All constructs merged into one factor.

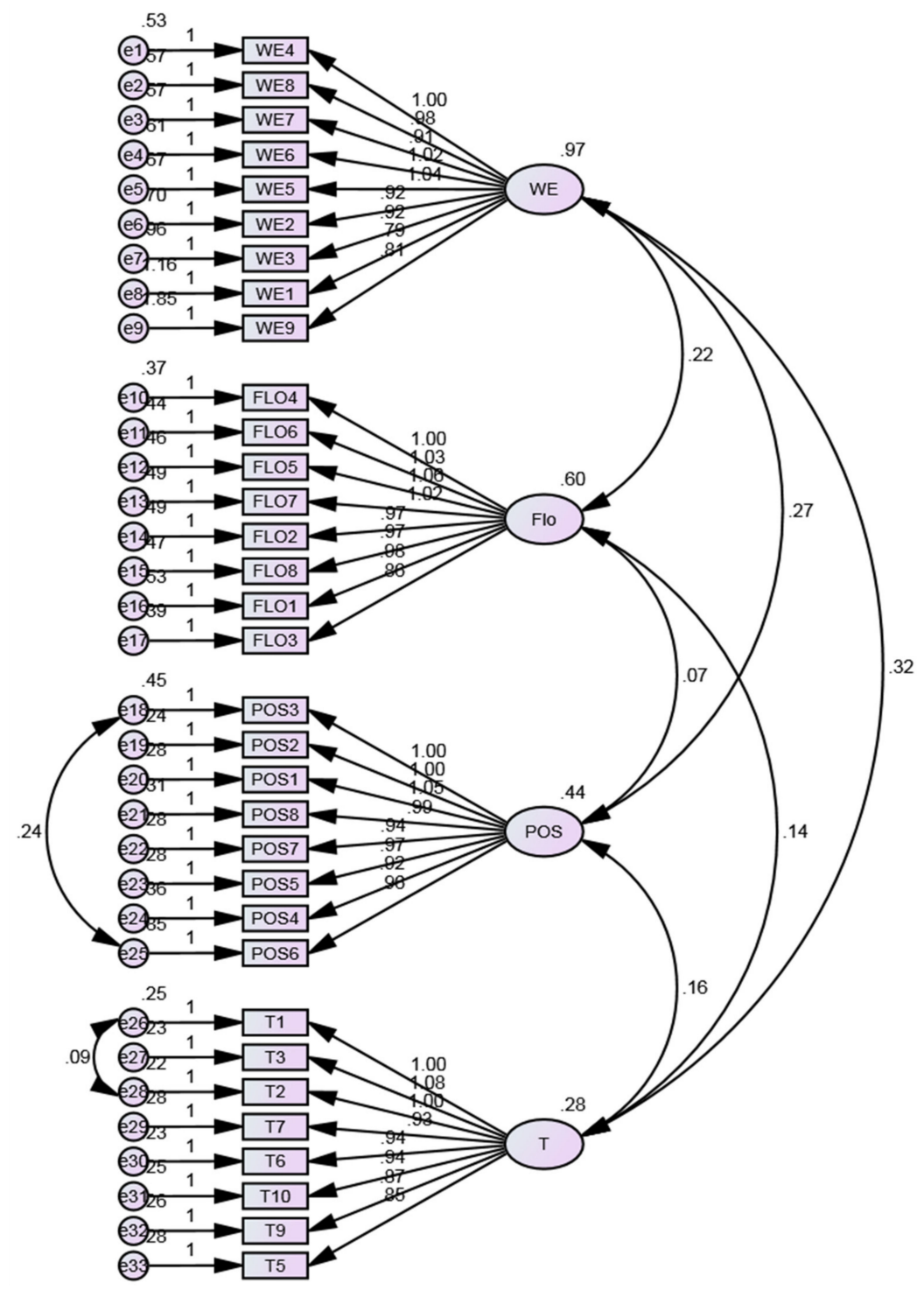

Figure 3. Measurement model fit indices.

Furthermore, the validity (convergent and discriminant) of measures was estimated by following Fornell and Larcker's recommendations [58]. Researcher [58] stated that the acceptable limit of CR (composite reliability) was $<0.80$ and AVE (average variance extract) was $<0.50$ for ensuring validity. All variables had convergent validity as the CR and AVE of all factors were greater than 0.70 and 0.50 respectively, in this study. Similarly, the criteria of discriminant validity was attained as the diagonal square root of AVE of all factors i.e., POS (0.74), work engagement (0.72), flourishing (0.75) and thriving (0.71) were larger than the inter-construct correlation values. Furthermore, discriminant validity was achieved as the AVE was greater than the MSV (maximum shared variance, Table 4). 
Table 4. Convergent and discriminant validity.

\begin{tabular}{|c|c|c|c|c|c|c|c|c|}
\hline & \multirow{2}{*}{ Constructs } & \multicolumn{3}{|c|}{ Convergent Validity } & \multicolumn{4}{|c|}{ Discriminant Validity } \\
\hline & & CR & AVE & MSV & 1 & 2 & 3 & 4 \\
\hline 1. & POS & 0.91 & 0.55 & 0.19 & 0.74 & & & \\
\hline 2. & Work Engagement & 0.90 & 0.52 & 0.36 & 0.40 & 0.72 & & \\
\hline 3. & Flourishing & 0.91 & 0.56 & 0.10 & 0.13 & 0.29 & 0.75 & \\
\hline 4. & Thriving & 0.89 & 0.51 & 0.36 & 0.44 & 0.61 & 0.32 & 0.71 \\
\hline
\end{tabular}

\subsection{Hypotheses Testing Results}

Our study examined the effect of perceived organizational support on work engagement through flourishing and thriving at work by using PROCESS Macros [59] (Model 4) with the 1000 bootstrapping technique. The outcomes of PROCESS demonstrated a significant direct effect of POS on work engagement $(\beta=0.27, t=5.62, p<0.001)$, supporting H1. The results showed that perceived organizational support positively influenced thriving $(\beta=0.30, t=10.61, p<0.001)$, hence supporting H2. Furthermore, the results of PROCESS analysis showed that thriving and work engagement were positively associated $(\beta=0.86, t=13.55, p<0.001)$, providing support for H3. These outcomes provide support for the mediator of thriving. Results of the simple mediation model specified that POS indirectly influenced work engagement by incorporating thriving as a mediator. This indirect effect was positive $(\beta=0.26, \mathrm{z}=8.34, p<0.001)$. The results of bootstrapping and the Sobel test were consistent with each other at $95 \% \mathrm{CI}[0.20,0.32]$ around the indirect effect excluding the zero point, supporting H4. Furthermore, the results showed that POS positively influenced flourishing ( $\beta=0.16$, $\mathrm{t}=3.45, p<0.001)$, supporting H5. Flourishing and work engagement were positively related $(\beta=0.27$, $t=6.11, p<0.001)$, providing support for H6. These outcomes provide support for the mediator of flourishing. The mediation results showed that flourishing mediated the POS and work engagement association. This mediating effect was positive $(\beta=0.04)$ and significant $(\mathrm{z}=2.98, p<0.001)$. The results of bootstrapping and Sobel test were consistent with each other at $95 \%$ CI $[0.01,0.09]$ across the indirect effect excluding the zero point. Therefore, H7 was supported (see Table 5; Figure 4).

Table 5. Results of hypothesized model.

\begin{tabular}{|c|c|c|c|c|c|c|}
\hline & \multicolumn{6}{|c|}{ Direct Effect } \\
\hline & \multicolumn{6}{|c|}{ Thriving (M) } \\
\hline & B & S.E & $\mathrm{T}$ & $\mathrm{P}$ & LLC1 & ULCI \\
\hline \multirow{7}{*}{$\operatorname{POS}(\mathrm{X})$} & 0.30 & 0.03 & 10.61 & 0.00 & 0.24 & 0.35 \\
\hline & \multirow{2}{*}{\multicolumn{6}{|c|}{$\begin{array}{l}\quad \mathrm{R}^{2}=0.15 \\
\text { Flourishing }(\mathrm{M})\end{array}$}} \\
\hline & & & & & & \\
\hline & 0.16 & 0.05 & 3.45 & 0.00 & 0.07 & 0.24 \\
\hline & \multicolumn{6}{|c|}{ Direct Effect } \\
\hline & \multicolumn{6}{|c|}{ Work Engagement (Y) } \\
\hline & B & S.E & $\mathrm{T}$ & $\mathrm{P}$ & LLC1 & ULCI \\
\hline $\operatorname{POS}(X)$ & 0.27 & 0.05 & 5.62 & 0.00 & 0.18 & 0.37 \\
\hline \multirow[t]{2}{*}{ Thriving (M) } & 0.86 & 0.06 & 13.55 & 0.00 & 0.74 & 0.99 \\
\hline & \multicolumn{6}{|c|}{$\mathrm{R}^{2}=0.34$} \\
\hline \multirow[t]{4}{*}{ Flourishing (M) } & 0.27 & 0.06 & 6.11 & 0.00 & 0.18 & 0.35 \\
\hline & \multicolumn{6}{|c|}{$\mathrm{R}^{2}=0.19$} \\
\hline & \multicolumn{6}{|c|}{ Indirect Effect of $X$ on $Y$} \\
\hline & Effect & S.E & Boc & $\mathrm{C} 1$ & Boo & LC1 \\
\hline Thriving & 0.26 & 0.03 & & & & \\
\hline \multirow[t]{3}{*}{ Flourishing } & 0.04 & 0.02 & & & & \\
\hline & \multicolumn{6}{|c|}{ Normal Theory Tests for Indirect Effect } \\
\hline & Value & SE & & & & \\
\hline Sobel (Thriving) & 0.26 & 0.03 & & & & \\
\hline Sobel (Flourishing) & 0.04 & 0.02 & & & & \\
\hline
\end{tabular}




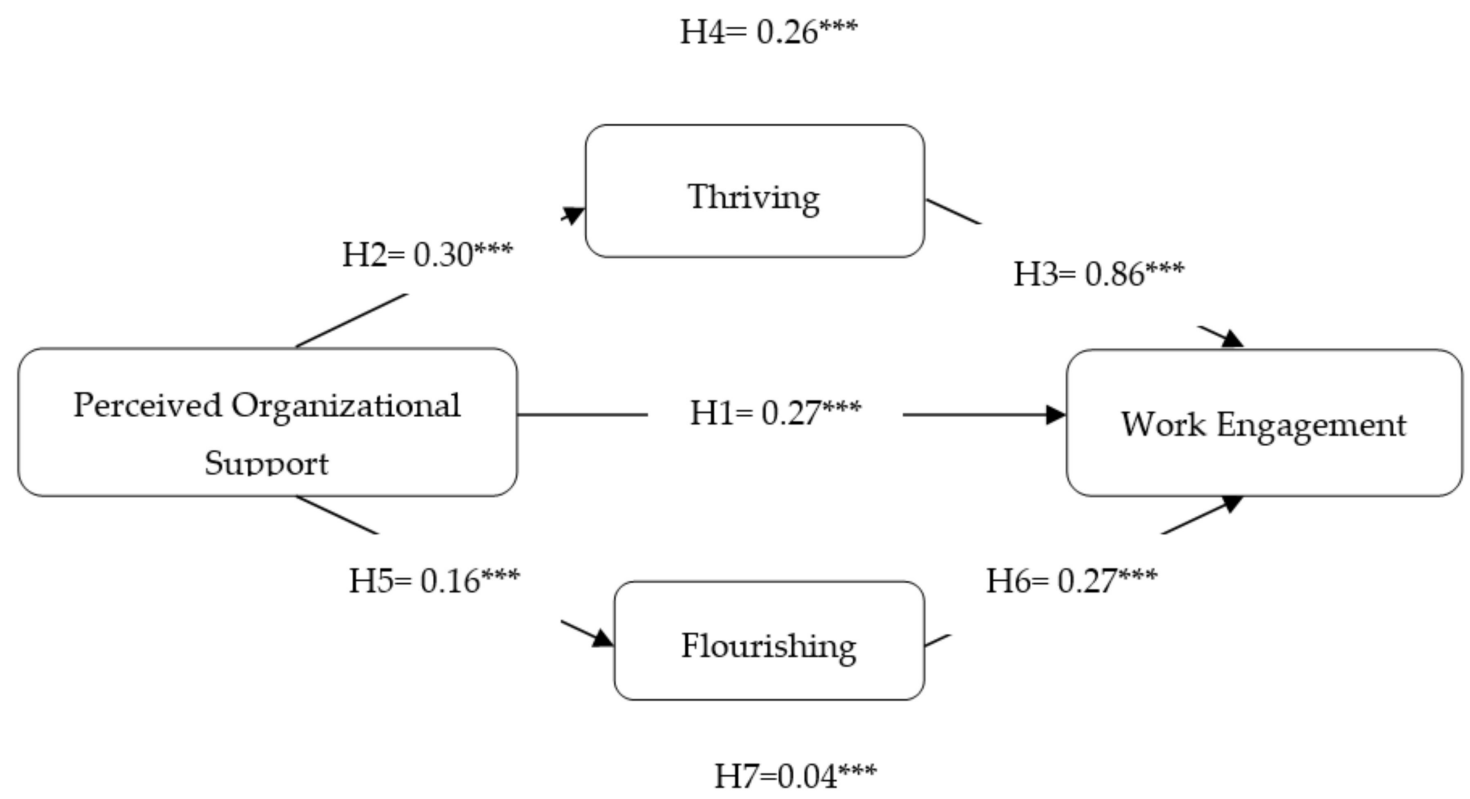

Figure 4. PROCESS estimated results. ${ }^{* * *} p<0.001$.

\section{Discussion}

This study drew on organizational support theory and conservation resource theory as a theoretical framework to examine the influence of POS on work engagement by flourishing and thriving in the organizational context of South Asia. First of all, our results indicated that POS is linked to work engagement and flourishing in a positive manner. When employees feel valued and fully supported by their organizations, they experience psychological, social, and emotional well-being and subsequently, this state leads them to high dedication and engagement with their work.

Thriving is a psychological state that arouses a sense of vitality and learning in individuals in the workplace [4]. Vitality is a feeling of aliveness and energy that creates enthusiasm for the tasks, whereas learning enhances confidence and capability through the acquisition of skills [60]. These two states of thriving are considered as adaptive function, which enables employees to develop personally and become adjusted to their work environment. According to Carmeli and Spreitzer [61], when employees are in the learning phase, they recognize and offer three ways by which thriving sets the stage for creativity and innovation to occur. First, when employees are learning and developing at work, they are in an ideal position to identify improvement prospects. They gain expertise through learning and this expertise drives creativity in them [61]. Moreover, the energy of thriving takes the employees toward exploration and investigation of new work procedures. In addition, few studies have identified the beneficial outcomes of flourishing at work such as creativity, subjective well-being, and lower turnover intention $[26,27]$. The current study revealed that perception of organizational support facilitates resources caravans and the creation of resources persuades employees to thrive in the working context, which enhances employee engagement toward their work [5]. The states of thriving and flourishing allows individuals to get involved in their work and enhances their engagement. These positive emotions motivate individuals to become more innovative [61]. Hence, open innovation becomes the source of creating new values [62]. Spithoven et al. [63] argued that external knowledge plays a vital role in optimizing in house innovations. Knowledge travels over several actors in the organization [64], thus leaves an inevitable impact on the organizational culture. Literature covering innovation discloses that employee' relationship skills, their expertise, thriving, and communication skills enhances the innovation process within the organization $[65,66]$. The mindset of an innovative culture paves the way for open innovation and enhances the employee's ability to respond rapidly to changing conditions [67]. Thriving at work is a personal resource that happens through the combination of feeling energetic and learned and POS encourages employees to generate cognitive (learning) 
and affective (vitality) resources [13]. It also protects their resources and allows them to develop new resources such as affective and cognitive resources [32], which prompts work engagement and innovation. Chatenier et al. [66] argued that behavioral characteristics provide the basis for having competencies for open innovation.

These results of the current study are in line with conservation resource theory [51] and the findings of Demerouti et al. [23] that when employees seek more resources at work, they flourish more in their life and are more engaged in their work. This study is consistent with prior studies that found that POS creates beneficial outcomes (i.e., subjective well-being, organizational trust, and career success [68-70]. In line with these studies, the findings of our research indicate that perception of organizational support leads to favorable outcomes (i.e., employee flourishing). Our study findings were also consistent with POS and work engagement linkage literature that there is positive relationship [71-73]. Our study also showed that POS is the major contributor to employee work engagement by validating this finding in the Asian context. The effect of the perception of organizational support on employee engagement in diverse cultures suggests that POS is a universally important factor for achieving productivity and sustainability in dynamic and uncertain business environments. Our study showed that flourishing employees are highly engaged in their work. This finding is consistent with prior studies that showed that flourishing is linked with positive outcome in the organizational setting $[23,26,27]$. Our results showed that when thriving employees perceived favorable support from their respective organizations, they consequently tended to exhibit more work engagement. Hence, our study findings replicate previous findings that perceived organizational support is positively related to thriving at work [40] and upon achieving the state of thriving, employees feel more immersed and engaged in their work [6]. The interplay of thriving with perceived organizational support and flourishing has remained scarcely researched. Hence, our results provide an interesting insight into the motivational roles of thriving and flourishing in the relationship between POS and work engagement. This implies that perception of organizational support allows employees to flourish and thrive, which in turn, advances their work engagement.

\section{Conclusions}

The present research examined the direct and indirect effect of POS on work engagement through flourishing and thriving in an organizational setting in the South Asian context. The study findings confirmed that POS was positively associated with employee flourishing, thriving, and work engagement. This study empirically revealed that working engagement is an important antecedent of flourishing and thriving. Furthermore, these results indicate that POS indirectly influences work engagement via flourishing and thriving as mediators. Therefore, organizations should focus on creating a supportive environment for their employees to enhance engagement at work by establishing emotional, psychological, and motivational states of flourishing and thriving at work.

\subsection{Theoretical Contributions}

In this study, we empirically examined the underlying mechanism of flourishing and thriving by examining the influence of perception of organizational support on work engagement and thus contribute to the positive organizational scholarship and organizational behavior domains in several ways. There are limited studies that have investigated the predictors and outcomes of flourishing [21,25]. Therefore, to address this gap, this study adds to the flourishing literature by introducing a predictor (i.e., POS) as well as outcome (i.e., work engagement). Our study also adds to the existing body of POS literature by introducing its new antecedent such as flourishing at work. Past studies have examined the beneficial outcomes of perceived organizational support while POS leading to employees' flourishing was not examined. Furthermore, the significant influence of POS on work engagement was consistent with past findings of Saks [37], who showed that perceived organizational support is an essential factor that enhances employee engagement. The empirical studies of Abid et al. [5] and van der Walt [43] showed that thriving is a strong contributor to work engagement, which is why 
our study empirically revealed that thriving is the key strongest indicator of work engagement in the organizational setting by validating the findings of these studies. Additionally, our results support the proposed positive association between POS and thriving of service employees. This is consistent with previous studies demonstrating the imperative role of POS in the thriving workforce. This research has added to the existing body of positive psychology literature by integrating thriving and flourishing as mediating factors that can demonstrate the influence of perception of organizational support on employee engagement. When employees are supported by their organizations, they experience flourishing, thriving, and high engagement by demonstrating its effectiveness in contributing toward their supportive organizations.

\subsection{Practical Implications}

The present study illustrates that when organizations provide support to their employees in terms of caring for their well-being and meeting their socio-emotional needs, this support creates positive results such as employee flourishing, thriving, and work engagement. Therefore, our study suggests that organizations have to increase the organizational perception of supporting their employees toward their organization in order to create a flourishing and thriving culture. The sample of service sector employees from a South Asian context showed that employees experience flourishing and thriving, which indicates that flourishing stimulates socio-psychological stability and thriving explores the affective and cognitive resources. Our study recommended that organizations can encourage managers to support their employees, for example, by trying to resolve any conflict in job responsibilities, having meetings with their subordinates on a regular basis, or providing emotional and materials resources to their staff when needed [74] and also by providing a training program that consists of four basic strategies such as sincerity, benevolence, experiential processing, and fairness [75] to provide a sense of POS among employees.

The current study attested that flourishing and thriving are positively associated with work engagement. Our study suggests that organization introduced initiatives such as broad sharing of information, providing feedback, creating a climate of civility, and decision-making discretion will promote vitality and learning in the work environment [18]. Freedom to make decisions can energize employees, which will positively influence their jobs. Empowering employees in this way gives them a stronger sense of responsibility and more learning opportunities. A respectful and positive environment promotes positive energy and eagerness on the part of employees to engage and contribute to the organization. Civility is the cornerstone that personnel need to talk freely and exchange ideas. Employees can thrive by gaining feedback on their performance as effective feedback generates thriving feelings as it allows people to know where they are in terms of abilities, and success. Feedback opens regular, directed, and two-way communication, which provides learning opportunities [76]. Furthermore, organizations can concentrate on coaching, training, and mentoring programmers, resilience and mindfulness training, and also recognize and improve the strengths of the individual, appreciating that these are useful to help employees to flourish. To increase the employees' work engagement, organizations should design their roles carefully.

\subsection{Limitations and Future Directions}

Our research has some practical implications as well as theoretical contributions, but there are several study limitations that we must concede. First, even though the data of the research variables were gathered at two different times (T1, T2) with a one-month lag, which may minimize specific process biases and transient response biases, the cross-sectional design also limits causal inferences. Employees with a higher perception of organizational support, for instance, can be expected more to flourish, thrive, and engage in work. Hence, future study in theoretical models might use experimental and longitudinal research to establish causality. Second, in this research, all data were gathered from the service sector of the collectivist context. This may constrain the study results from being generalized to other different cultures. Furthermore, the concept of flourishing at work differs across 
various cultural settings. Future studies might also examine whether the results of this study can be extended to cross-cultural contexts by gathering data from different countries and industries to improve the generalizability of these result. Third, quantitative data were used in this study to analyze the association between research variables. This study recommended that future studies may use a mixed-method or qualitative approach for detailed exploration of the interplay of study variables. Fourth, in this study, we examined the outcomes of flourishing at the individual level. Future studies may also check the influence of flourishing such as organizational innovation and performance (organizational level) as well as team effectiveness (team-level).

Author Contributions: Conceptualization, M.Y.I. and G.A.; Methodology, M.Y.I. and G.A.; Software, N.S.E.; Validation, N.S.E. and G.A.; Formal Analysis, N.S.E. Investigation, M.Y.I. and G.A.; Resources, M.Y.I. and G.A.; Data Curation, M.Y.I. and G.A.; Writing-Original Draft Preparation, M.Y.I. and G.A.; Writing-Review \& Editing, N.S.E., F.A. and S.I.; Visualization, N.S.E. Supervision, G.A.; Project Administration, G.A.; Funding Acquisition, M.Y.I. and G.A. All authors have read and agreed to the published version of the manuscript.

Funding: This research received no external funding.

Conflicts of Interest: The authors declare no conflict of interest.

\section{Abbreviations}

POS Perceived organizational support

OST Organizational support theory

COR Conservation of resource theory

\section{Appendix A Questionnaire}

\section{Perceived Organizational Support}

1. My organization strongly considers my goals and values.

2. My organization really cares about my well-being.

3. My organization shows very little concern for me. ${ }^{\circledR}$

4. My organization would forgive an honest mistake on my part.

5. My organization cares about my opinions.

6. If given the opportunity, my organization would take advantage of me. ${ }^{\circledR}$

7. Help is available from my organization when I have a problem.

8. My organization is willing to help me when I need a special favor.

\section{Thriving at Work}

1. I find myself learning often.

2. I continue to learn more and more as time goes by.

3. I see myself continually improving

4. I am not learning.

5. I have developed a lot as a person.

6. I feel alive and vital.

7. I have energy and spirit.

8. I do not feel very energetic. ${ }^{\circledR}$

9. I feel alert and awake.

10. I am looking forward to each new day.

\section{Flourishing}

1. I lead a purposeful and meaningful life.

2. My social relationships are supportive and rewarding.

3. I am engaged and interested in my daily activities.

4. I actively contribute to the happiness and well-being of others.

5. I am competent and capable in the activities that are important to me.

6. I am a good person and live a good life.

7. I am optimistic about my future.

8. People respect me. 


\section{Work Engagement}

1. At my work, I feel bursting with energy.

2. At my job, I feel strong and vigorous.

3. When I get up in the morning, I feel like going to work.

4. I am enthusiastic about my job

5. My job inspires me.

6. I am proud of the work that I do.

7. I feel happy when I am working intensely.

8. I am immersed in my work.

9. I get carried away when I am working.

Note ${ }^{\circledR}=$ Reverse coded item.

\section{References}

1. Prem, R.; Ohly, S.; Kubicek, B.; Korunka, C. Thriving on challenge stressors? Exploring time pressure and learning demands as antecedents of thriving at work. J. Organ. Behav. 2016, 38, 108-123. [CrossRef]

2. Abid, G.; Contreras, F.; Ahmed, S.; Qazi, T. Contextual factors and organizational commitment: Examining the mediating role of thriving at work. Sustainability 2019, 11, 4686. [CrossRef]

3. Chang, W.; Busser, J.A. Hospitality career retention: The role of contextual factors and thriving at work. Int. J. Contemp. Hosp. Manag. 2020, 32, 193-211. [CrossRef]

4. Spreitzer, G.; Sutcliffe, K.; Dutton, J.; Sonenshein, S.; Grant, A.M. A socially embedded model of thriving at work. Organ. Sci. 2005, 16, 537-549. [CrossRef]

5. Abid, G.; Sajjad, I.; Elahi, N.S.; Farooqi, S.; Nisar, A. The influence of prosocial motivation and civility on work engagement: The mediating role of thriving at work. Cogent Bus. Manag. 2018, 5, 1493712. [CrossRef]

6. Kleine, A.K.; Rudolph, C.W.; Zacher, H. Thriving at work: A meta-analysis. J. Organ. Behav. 2019, 40, 973-999. [CrossRef]

7. Elahi, N.S.; Abid, G.; Arya, B.; Farooqi, S. Workplace behavioral antecedents of job performance: Mediating role of thriving. Serv. Ind. J. 2019, 40, 755-776. [CrossRef]

8. Basinska, B.A. Thriving in a multicultural workplace. In Intercultural Interactions in the Multicultural Workplace; Rozkwitalska, M., Sułkowski, Ł., Magala, S., Eds.; Springer International Publishing: New York, NY, USA, 2017; pp. 109-121.

9. Shahid, S.; Muchiri, M.K.; Walumbwa, F.O. Mapping the antecedents and consequences of thriving at work. Int. J. Organ. Anal. 2020. [CrossRef]

10. Vivek, S.A.; Raveeendran, D. Thriving at workplace by bank managers: An empirical study of public and private sector banks. Int. J. Entrep. Dev. Stud. 2017, 5, 1-11.

11. Riaz, S.; Xu, Y.; Hussain, S. Understanding employee innovative behavior and thriving at work: A Chinese perspective. Adm. Sci. 2018, 8, 46. [CrossRef]

12. Qaiser, S.; Abid, G.; Arya, B.; Farooqi, S. Nourishing the bliss: Antecedents and mechanism of happiness at work. Total Qual. Manag. Bus. Excell. 2018. [CrossRef]

13. Zhai, Q.; Wang, S.; Weadon, H. Thriving at work as a mediator of the relationship between workplace support and life satisfaction. J. Manag. Organ. 2017, 26, 168-184. [CrossRef]

14. Abid, G.; Khan, B.; Hong, M.C.W. Thriving at work: How a fairness perception matter for employee's thriving and job satisfaction. In Academy of Management Proceedings; Academy of Management: Briarcliff Manor, NY, USA, 2016; Volume 2016, p. 11948.

15. Walumbwa, F.O.; Muchiri, M.K.; Misati, E.; Wu, C.; Meiliani, M. Inspired to perform: A multilevel investigation of antecedents and consequences of thriving at work. J. Organ. Behav. 2017, 3, $249-261$. [CrossRef]

16. Paterson, T.A.; Luthans, F.; Jeung, W. Thriving at work: Impact of psychological capital and supervisor support. J. Organ. Behav. 2014, 35, 434-446. [CrossRef]

17. Eisenberger, R.; Huntington, R.; Hutchison, S.; Sowa, D. Does pay for performance increase or decrease perceived self-determination and intrinsic motivation? J. Personal. Soc. Psychol. 1986, 77, 1026-1040. [CrossRef]

18. Porath, C.; Spreitzer, G.; Gibson, C.; Garnett, F.G. Thriving at work: Toward its measurement, construct validation, and theoretical refinement. J. Organ. Behav. 2012, 33, 250-275. [CrossRef] 
19. Diener, E.; Wirtz, D.; Tov, W.; Kim-Prieto, C.; Choi, D.; Oishi, S.; Biswas-Diener, R. New wellbeing measures: Short scales to assess flourishing and positive and negative feelings. Soc. Indic. Res. 2010, 97, 143-156. [CrossRef]

20. Huppert, F.A.; So, T. Flourishing across Europe: Application of a new conceptual framework for defining well-being. Soc. Indic. Res. 2013, 110, 837-861. [CrossRef]

21. Abid, G.; Ijaz, S.; Butt, T.; Farooqi, S.; Rehmat, M. Impact of perceived internal respect on flourishing: A sequential mediation of organizational identification and energy. Cogent Bus. Manag. 2018, 5, 1507276. [CrossRef]

22. Janse van Rensburg, C.; Rothmann, S.; Diedericks, E. Supervisor support, flourishing, and intention to leave in a higher education setting. J. Psychol. Afr. 2017, 27, 412-419. [CrossRef]

23. Demerouti, E.; Bakker, A.B.; Gevers, J.M. Job crafting and extra-role behavior: The role of work engagement and flourishing. J. Vocat. Behav. 2015, 91, 87-96. [CrossRef]

24. Keyes, C.L.M. The mental health continuum: From languishing to flourishing in life. J. Health Soc. Behav. 2002, 43, 207-222. [CrossRef] [PubMed]

25. Bakker, A.B.; Schaufeli, W.B. Positive organizational behavior: Engaged employees in flourishing organizations. J. Organ. Behav. 2008, 29, 147-154. [CrossRef]

26. Butt, T.H.; Abid, G.; Arya, B.; Farooqi, S. Employee energy and subjective well-being: A moderated mediation model. Serv. Ind. J. 2018, 40, 133-157. [CrossRef]

27. Rautenbach, C.; Rothmann, S. Antecedents of flourishing at work in a fast-moving consumer goods company. J. Psychol. Afr. 2017, 27, 227-234. [CrossRef]

28. Blau, P.M. Exchange and Power in Social Life; Wiley: New York, NY, USA, 1964.

29. Gouldner, A.W. The norm of reciprocity: A preliminary statement. Am. Sociol. Rev. 1960, 25, 161-179. [CrossRef]

30. Eisenberger, R.; Armeli, S.; Rexwinkel, B.; Lynch, P.D.; Rhoades, L. Reciprocation of perceived organizational support. J. Appl. Psychol. 2001, 86, 42-51. [CrossRef]

31. Hobfoll, S.E. Conservation of resources: A new attempt at conceptualizing stress. Am. Psychol. 1989, 44, 513-524. [CrossRef]

32. Hobfoll, S.E. The influence of culture, community, and the nested self in the stress process: Advancing conservation of resources theory. Appl. Psychol. An Int. Rev. 2001, 50, 337-370. [CrossRef]

33. Hakkak, M.; Ghodsi, M. Investigating the relation between job satisfaction, perceived organizational support and organizational commitment. Int. J. Manag. Humanit. Sci. 2013, 2, 513-520.

34. Schaufeli, W.B.; Salanova, M.; González-Romá, V.; Bakker, A.B. The measurement of engagement and burnout: A two sample confirmatory factor analytic approach. J. Happiness Stud. 2002, 3, 71-92. [CrossRef]

35. Byrne, Z.S.; Hochwarter, W.A. Perceived organizational support and performance relationships across levels of organizational cynicism. J. Manag. Psychol. 2008, 23, 54-72. [CrossRef]

36. Eisenberger, R.; Stinglhamber, F. Perceived Organizational Support: Fostering Enthusiastic and Productive Employees; APA Books: Washington, DC, USA, 2011.

37. Saks, A.M. Antecedents and consequences of employee engagement revisited. J. Organ. Eff. People Perform. 2019, 6, 19-38. [CrossRef]

38. Ali, F.H.; Rizavi, S.S.; Ahmed, I.; Rasheed, M. Effects of perceived organizational support on organizational citizenship behavior-Sequential mediation by well-being and work engagement. J. Punjab Univ. Hist. Soc. 2018, 31, 55-63.

39. Murthy, R.K. Perceived organizational support and work engagement. Int. J. Appl. Res. 2017, 3, 738-740.

40. Abid, G.; Zahra, I.; Ahmed, A. Mediated mechanism of thriving at work between perceived organization support, innovative work behavior and turnover intention. Pak. J. Commer. Soc. Sci. 2015, 9, 982-998.

41. Rhoades, L.; Eisenberger, R. Perceived organizational support: A review of the literature. J. Appl. Psychol. 2002, 87, 698-714. [CrossRef]

42. Bakker, A.B.; Albrecht, S.L.; Leiter, M.P. Key questions regarding work engagement. Eur. J. Work Organ. Psychol. 2011, 20, 4-28. [CrossRef]

43. Van der Walt, F. Workplace spirituality, work engagement and thriving at work. SA J. Ind. Psychol. 2018, 44, 1-10. [CrossRef]

44. Ryan, R.M.; Bernstein, J.H. Vitality. In Character Strengths and Virtues: A Handbook and Classification; Peterson, C., Seligman, M.E.P., Eds.; Oxford University Press: New York, NY, USA, 2004. 
45. Demerouti, E.; Bakker, A.B.; Nachreiner, F.; Schaufeli, W.B. The job demands resources model of burnout. J. Appl. Psychol. 2001, 86, 499-512. [CrossRef]

46. Halbesleben, J.R.; Harvey, J.; Bolino, M.C. Too engaged? A conservation of resources view of the relationship between work engagement and work interference with family. J. Appl. Psychol. 2009, 94, 1452-1465. [CrossRef] [PubMed]

47. Hakanen, J.J.; Perhoniemi, R.; Toppinen-Tanner, S. Positive gain spirals at work: From job resources to work engagement, personal initiative and work-unit. J. Vocat. Behav. 2008, 73, 78-91. [CrossRef]

48. Vigoda-Gadot, E.; Eldor, L.; Schohat, L.M. Engage them to public service: Conceptualization and empirical examination of employee engagement in public administration. Am. Rev. Public Adm. 2013, 43, 518-538. [CrossRef]

49. Fredrickson, B.L.; Losada, M.F. Positive affect and the complex dynamics of human flourishing. Am. Psychol. 2005, 60, 678-686. [CrossRef]

50. Fredrickson, B.L. The role of positive emotions in positive psychology: The broaden-and-build theory of positive emotions. Am. Psychol. Spec. Issue 2001, 56, 218-226. [CrossRef]

51. Hobfoll, S.E.; Freedy, J.; Lane, C.; Geller, P. Conservation of social resources: Social support resource theory. J. Soc. Pers. Relatsh. 1990, 7, 465-478. [CrossRef]

52. Podsakoff, P.M.; MacKenzie, S.B.; Lee, J.-Y.; Podsakoff, N.P. Common method biases in behavioral research: A critical review of the literature and recommended remedies. J. Appl. Psychol. 2003, 88, 879-903. [CrossRef]

53. Eisenberger, R.; Cummings, J.; Armeli, S.; Lynch, P. Perceived organizational support 2011, discretionary treatment, and job satisfaction. J. Appl. Psychol. 1997, 82, 812. [CrossRef]

54. Kaiser, H.F. An index of factorial simplicity. Psychometrika 1974, 39, 31-36. [CrossRef]

55. Kline, P. An Easy Guide to Factor Analysis; Routledge: New York, NY, USA, 1994.

56. Hulland, J. Use of partial least squares (PLS) in strategic management research: A review of four recent studies. Strateg. Manag. J. 1999, 20, 195-204. [CrossRef]

57. Hu, L.T.; Bentler, P.M. Cutoff criteria for fit indexes in covariance structure analysis: Conventional criteria versus new alternatives. Struct. Equ. Model. Multidiscip. J. 1999, 6, 1-55. [CrossRef]

58. Fornell, C.; Larcker, D.F. Structural equation models with unobservable variables and measurement error: Algebra and statistics. J. Mark. Res. 1981, 18, 382-388. [CrossRef]

59. Hayes, A.F. Methodology in the social sciences. In Introduction to Mediation, Moderation, and Conditional Process Analysis: A Regression-Based Approach; Guilford Press: New York, NY, USA, 2013.

60. Edmondson, A. Psychological Safety and Learning Behavior in Work Teams. Adm. Sci. Q. 1999, 44, 350-383. [CrossRef]

61. Carmeli, A.; Spreitzer, G.M. Trust, Connectivity, and Thriving: Implications for Innovative Behaviors at Work. J. Creat. Behav. 2009, 43, 169-191. [CrossRef]

62. Yun, J.J.; Zhao, X.; Jung, K.; Yigitcanlar, T. The Culture for Open Innovation Dynamics. Sustainability 2020, 12, 5076. [CrossRef]

63. Spithoven, A.; Clarysse, B.; Knockaert, M. Building absorptive capacity to organise inbound open innovation in traditional industries. Technovation 2010, 30, 130-141. [CrossRef]

64. Yun, J.J.; Zhao, X.; Park, K.; Shi, L. Sustainability Condition of Open Innovation: Dynamic Growth of Alibaba from SME to Large Enterprise. Sustainability 2020, 12, 4379. [CrossRef]

65. Iqbal, Z.A.; Abid, G.; Contreras, F.; Hassan, Q.; Zafar, R. Ethical Leadership and Innovative Work Behavior: The Mediating Role of Individual Attributes. J. Open Innov. Technol. Mark. Complex. 2020, 6, 68. [CrossRef]

66. Chatenier, E.D.; Verstegen, J.A.; Biemans, H.J.; Mulder, M.; Omta, O.S.F. Identification of competencies for professionals in open innovation teams. RED Manag. 2010, 40, 271-280.

67. Yun, J.J.; Lee, M.; Park, K.; Zhao, X. Open innovation and serial entrepreneurs. Sustainability 2019, $11,5055$. [CrossRef]

68. Caesens, G.; Stinglhamber, F.; Demoulin, S.; De Wilde, M. Perceived organizational support and employees' well-being: The mediating role of organizational dehumanization. Eur. J. Work Organ. Psychol. 2017, 26, 527-540. [CrossRef]

69. Hayunintyas, R.F.; Do, B.R.; Sudiro, A.; Irawanto, D.W. Organizational justice and effective organizational commitment mediated by organizational trust and perceived organizational support: Study at the largest poultry industry company in Indonesia. Asia Pac. Manag. Bus. Appl. 2018, 6, 154-163. [CrossRef] 
70. Książek, D.; Rożenek, P.; Warmuz, S. The impact of perceived organizational support on trust. A case study of a state university. World Sci. News 2016, 48, 108-118.

71. Del Líbano, M.; Llorens, S.; Salanova, M.; Schaufeli, W.B. About the dark andbright sides of self-efficacy: Workaholismand work engagement. Span. J. Psychol. 2012, 15, 688-701. [CrossRef] [PubMed]

72. Kinnunen, U.; Feldt, T.; Makikangas, A. Testing the effort-reward imbalance model among Finnish managers: The role of perceived organizational support. J. Occup. Health Psychol. 2008, 13, 114-127. [CrossRef]

73. Park, Y.; Lim, D.H.; Kim, W.; Kang, H. Organizational Support and Adaptive Performance: The Revolving Structural Relationships between Job Crafting, Work Engagement, and Adaptive Performance. Sustainability 2020, 12, 4872. [CrossRef]

74. Newman, A.; Thanacoody, R.; Hui, W. The impact of employee perceptions of training on organizational commitment and turnover: A case of multinationals in the Chinese service sector. Pers. Rev. 2012, 41, 56-72. [CrossRef]

75. Spreitzer, G.; Porath, C.L. Self-Determination as a nutriment for thriving: Building an integrative model of human growth at work. In Oxford Handbook of Work Engagement, Motivation, and Self-Determination Theory; Gagne, M., Ed.; Oxford University Press: Oxford, UK, 2014.

76. Gonzalez-Morales, M.G.; Kernan, M.C.; Becker, T.E.; Eisenberger, R. Defeating abusive supervision: Training supervisors to support subordinates. J. Occup. Health Psychol. 2016, 23, 151-162. [CrossRef]

(C) 2020 by the authors. Licensee MDPI, Basel, Switzerland. This article is an open access article distributed under the terms and conditions of the Creative Commons Attribution (CC BY) license (http://creativecommons.org/licenses/by/4.0/). 